\title{
MEASUREMENT AND INTERPRETATION OF SYNOVIAL FLUID VISCOSITIES
}

BY

\author{
C. H. BARNETT* \\ Anatomy Department, St. Thomas's Hospital Medical School, London
}

The highly viscous nature of synovial fluid is one of its most striking physical properties. Since the viscosity is altered in many joint diseases (Ropes and Bauer, 1953) and pathological fluid is usually obtainable without difficulty, one would expect that the determination of viscosities would be a common procedure. In fact, this is rarely undertaken, either because many of the measuring techniques advocated in the literature seem very elaborate or because the figures obtained are difficult to interpret. By using simple apparatus and recording the findings graphically, however, results may be achieved that are of value in assessing objectively the progress of articular disease or the response to therapy.

\section{Material}

Synovial fluid was aspirated from the apparently normal knee joints of six post-mortem subjects, within 3 hours of death. All were under 40 years of age, showed no oedema, and died of non-articular conditions. Although such fluid could not strictly be regarded as "normal", it was considered that aspiration of healthy joints during life was unjustifiable. Fluid was also obtained, under general anaesthesia, from the joints of two sacred baboons, the only large primate species available. In addition, fluid was aspirated from the diseased knee joints of patients who were receiving intraarticular medication.

\section{Methods}

All fluids were brought to a temperature of $20^{\circ} \mathrm{C}$. and the viscosities estimated the same day. A modification

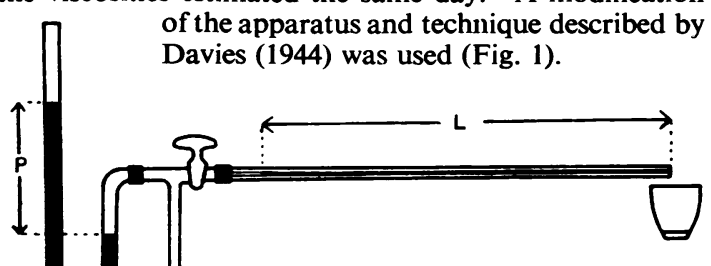

Fig. 1.-Apparatus. The tap being closed, air is pumped in from the stem of the T-tube until the pressure desired $(P)$ is indicated by the mercury manometer. The tap is then opened and the fluid column (length $L$ ) is blown out of the capillary-tube. The time (T) for complete expulsion of the fluid depends on its viscosity.

\footnotetext{
- In receipt of a grant from the Nuffield Foundation.
}

A capillary-tube of known, uniform radius $(R \mathrm{~cm}$.) was filled almost completely with the fluid under test and placed in a horizontal stand. The length of the column of fluid was measured $(\mathrm{L} \mathrm{cm}$.), and one end of the tube was connected to a manometer and pump by means of a T-piece fitted with a tap. This was kept closed until the manometer indicated that the pump had raised the pressure to a predetermined level $(\mathrm{P} \mathrm{cm}$. $\mathrm{Hg})$. It was then opened and the pump was started again momentarily to restore the pressure level. The fluid was expelled from the tube into a small container, the time ( $T$ sec.) for complete expulsion being measured with a stop-watch. The experiment was repeated at least eight times using different pressures, so that the times ranged evenly from a few seconds up to 2 or 3 minutes. The fluid that accumulated in the container could be used again if the total quantity available was very small.

The following formula was used to calculate the viscosities:

$$
\text { Viscosity in poises }=\frac{3,307 \times \mathbf{P} \times T \times \mathbf{R}^{2}}{\mathbf{L}^{2}}
$$

This equation is over-simplified; for example, it takes no account of surface tension effects (see Davies, 1944). However, tests with lubricating oils of known viscosity showed that the error involved did not exceed $10 \mathrm{per}$ cent. of the correct value (Fig. 2). The correct equation includes certain constants, for example, the specific gravity of mercury; these are incorporated in the amount

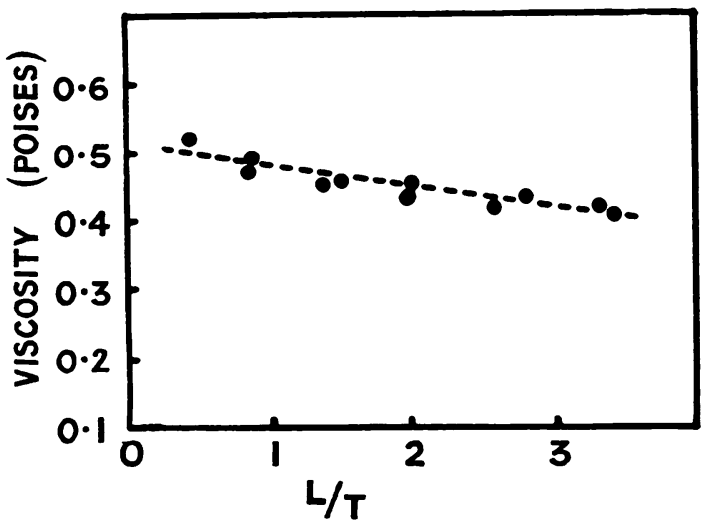

Fig. 2.-Viscosity of a standard lubricating oil as determined by the present technique. There is apparently a very slight fall in viscosity when the fluid is expelled more quickly, i.e. as the rate of shear between adjacent molecules of the fluid increases (see text). 
3,307 above. If one capillary-tube is always used, $R$ is also constant $; 0.0325 \mathrm{~cm}$. is a suitable standard radius.

The viscosity of some fluids was measured by means of a rolling-ball viscometer (Barnett, 1957). This gave the value at high rates of shear.

\section{Results}

Like other disperse systems, synovial fluid exhibits non-Newtonian properties unless it is very dilute (Hermans, 1953; Ogston and Stanier, 1953). It behaves as an extremely thick oil when joint surfaces are being sheared very slowly upon one another, but becomes progressively less viscous as the rate of shear increases. Thus, in the capillary-tube method used here, a low figure for the viscosity is obtained if a high expulsion pressure-which empties the tube rapidly-is applied. On the other hand, if the pressure is low, the fluid may take many minutes to be expelled-longer than the thickest lubricating oil in general use.

This anomalous viscosity may be expressed in several ways (Ogston and Stanier, 1953; Sunblad, 1954; Blair, Williams, Fletcher and Markham, 1954). A simple method used by the author was to plot the various viscosity readings against the corresponding average rate of expulsion of the column of fluid (i.e. L/T). Admittedly, this method introduced an undesirable feature in that both the factors $\mathrm{L}$ and $\mathrm{T}$ were invoked twice-once in the formula for calculating the viscosity, once in the term for the rate of expulsion. However, this defect was outweighed by the ease of interpretation of the results, for it can readily be understood that the fraction L/T is an index of the "rate of shear" of the molecules of fluid upon one another and upon the inner surface of the capillary-tube.
The curves obtained were very similar to those published by Ogston and Stanier (1953), in which the calculated viscosities were plotted against the rate of shear of synovial fluid between a stationary and a moving curved surface (Fig. $3 a, 3 b$ ).

In theory, the points should all lie on a line parallel to the axis of abscissae, if a true (Newtonian) fluid is being tested, for the viscosity should remain constant irrespective of the rate of emptying the tube. The apparent slight fall in viscosity as the rate increased (Fig. 2) resulted from the use of an incomplete formula as well as from defects in the method of graphic representation.

It was found convenient to plot the viscosity figures on double-logarithmic graph paper (Fig. $3 c$ ); the points then fell along a straight line except at high rates of expulsion. This regression line could be calculated by the method of least squares if desired, but it was usually estimated with sufficient accuracy by eye. The range of scatter in a typical graph is shown in Fig. $3 c$; the points are omitted from other figures. Translucent graph paper was used so that several graphs could readily be compared by superimposition.

Two properties of synovial fiuid could be evaluated by studying these graphs. Firstly, the viscosity of a given sample at any particular rate of expulsior was read off and compared with the corresponding figure for a normal fluid or that removed from the same joint at an earlier date. Secondly, the degree of anomalous viscosity was indicated by the slope of the linear graph, which was steep when normal synovial fluid was used but more nearly parallel to the axis of abscissae when the fluid had been taken from arthritic joints. Pathological fluids commonly contain molecules that are incompletely

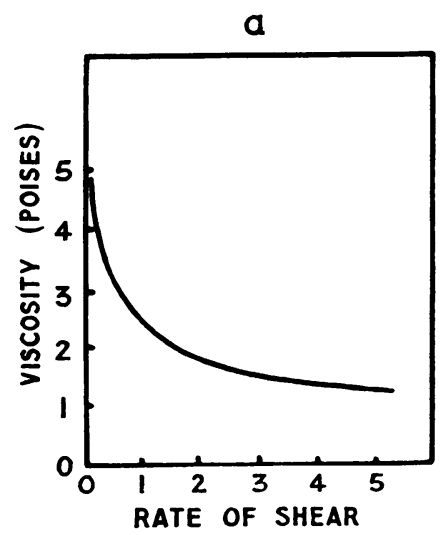

Fig. 3(a).-Viscosities of synovial fluid at different rates of shear (after Ogston and Stanier)

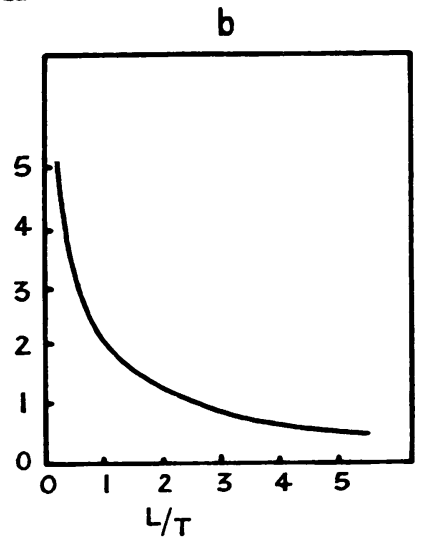

Fig. 3(b).-Viscosities of synovial fluid at different average rates of expulsion from the capillary-tube.

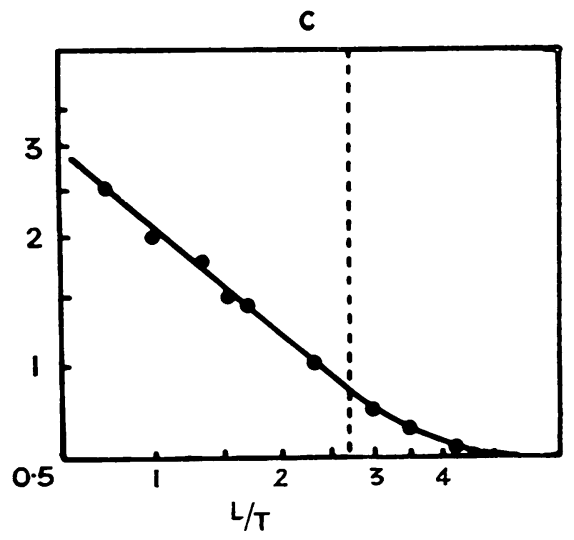

Fig. 3(c).-Similar viscosity figures plotted on double-logarithmic scale. All points to the left of the dotted line fall along a straight line. 
polymerized (Ragan and Meyer, 1949) and thus behave more like Newtonian fluids.

In Fig. 4 are shown the graphs derived from the knee fluids of the six post-mortem subjects and the two living baboons. These normal synovial fluids did not form a homogeneous group, but all were considerably more viscous than the fluids customarily aspirated from arthritic knees.

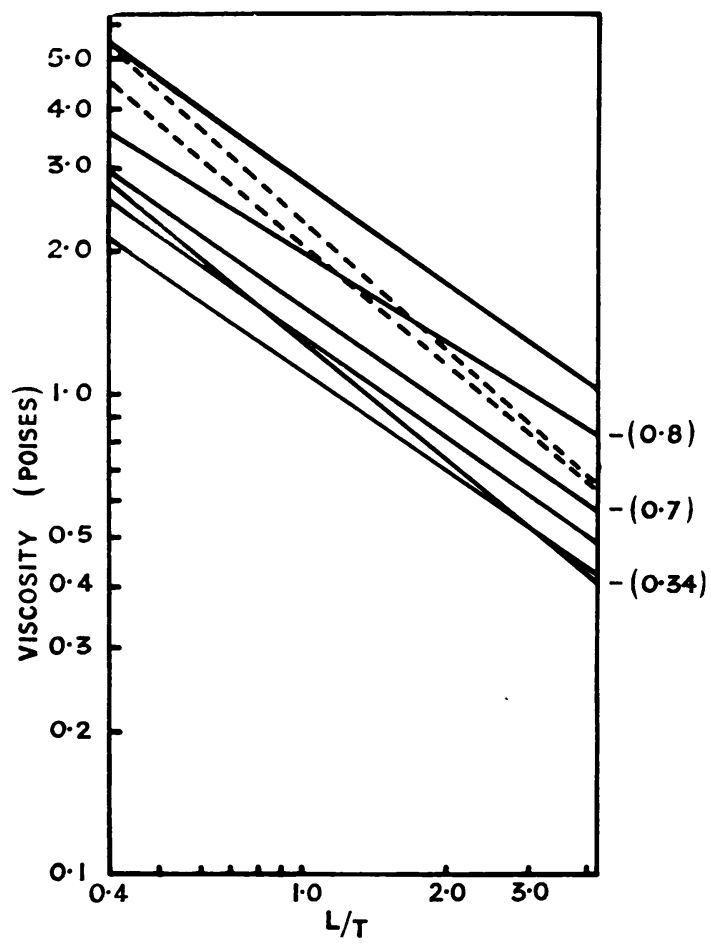

Fig. 4.-Viscosity figures of eight normal synovial fluids determined at different rates of expulsion from the capillary-tube (see text). Note that all fluids behave as if they are much less viscous if the rate of expulsion is increased. Numbers in brackets refer to the viscosities as determined by a rolling-ball viscometer. Baboon fluids dotted.

Serial studies of the knee fluids of two patients are shown in Figs 5 and 6 (overleaf).

Although the synovial fluid viscosity of the latter patient was raised towards the normal figure as a result of the intra-articular therapy, it fell rapidly when treatment was stopped. The former patient showed very little response to treatment, the viscosity remaining subnormal throughout.

There was no evidence that the viscosity of synovial fluid is subject to large irregular fluctuations as is commonly believed. Unpublished observations on a number of other patients indicate that synovial fluid remains sufficiently constant for valid comparison to be made of the viscosities before and after treatment.
Some of the viscosities at high rates of shear, obtained by use of the rolling-ball viscometer, are indicated by numbers in brackets in Fig. 4 .

\section{Discussion}

Before considering the interpretation of the results, it is necessary to discuss the statements concerning synovial fluid viscosity that are recorded in the literature. In view of the anomalous properties of the fluid, a single figure (for example, an observation that a particular sample has a viscosity of 0.5 poises) is almost meaningless unless the corresponding rate of shear is also given. For this reason, the findings of Dixon and Bywaters (1953), Bauer, Ropes, and Waine (1940), and many other workers are difficult to evaluate. Single figures may in fact be misleading. Some fluids studied by the author differed considerably at low rates of shear, but-because of unequal degrees of polymerization-had almost identical viscosities at high rates, as determined by the rolling-ball viscometer (see Fig. 4).

Synovial fluid is less anomalous in behaviour at high rates of shear-presumably because the long molecular chains have become untwisted and slide freely upon one another-and some of the recorded figures may refer to the viscosity measured at these high rates. It is doubtful, however, whether such figures have great physiological significance. The maintenance of a viscous synovial film between moving articular surfaces is necessary to prevent excessive wear and tear (MacConaill, 1932; Jones, 1934; Barnett, 1956). A fluid of reduced viscosity may provide adequate lubrication when a joint is moving rapidly but the film is liable to be dispersed as soon as movement is slowed (Charnley, 1954). For this reason the viscosity measured at low rates of shear is more significant than that at high rates.

The degree of polymerization of the hyaluronic acid molecules in synovial fluid is important also. Fully polymerized molecules play an important part in preventing direct contact between articular surfaces that are forcibly compressed together (Ropes, Robertson, Rossmeisl, Peabody, and Bauer, 1947).

One reason why viscosity measurement is not a common procedure in assessing joint disorders is the widespread impression that the fluid within a joint is liable to fluctuate from day to day in its physical properties and to differ markedly from that removed from the corresponding joint of another person. The author believes that this variability has been exaggerated, mainly through a failure to appreciate the properties of non-Newtonian fluids. Thus the scatter in the results obtained by Davies 

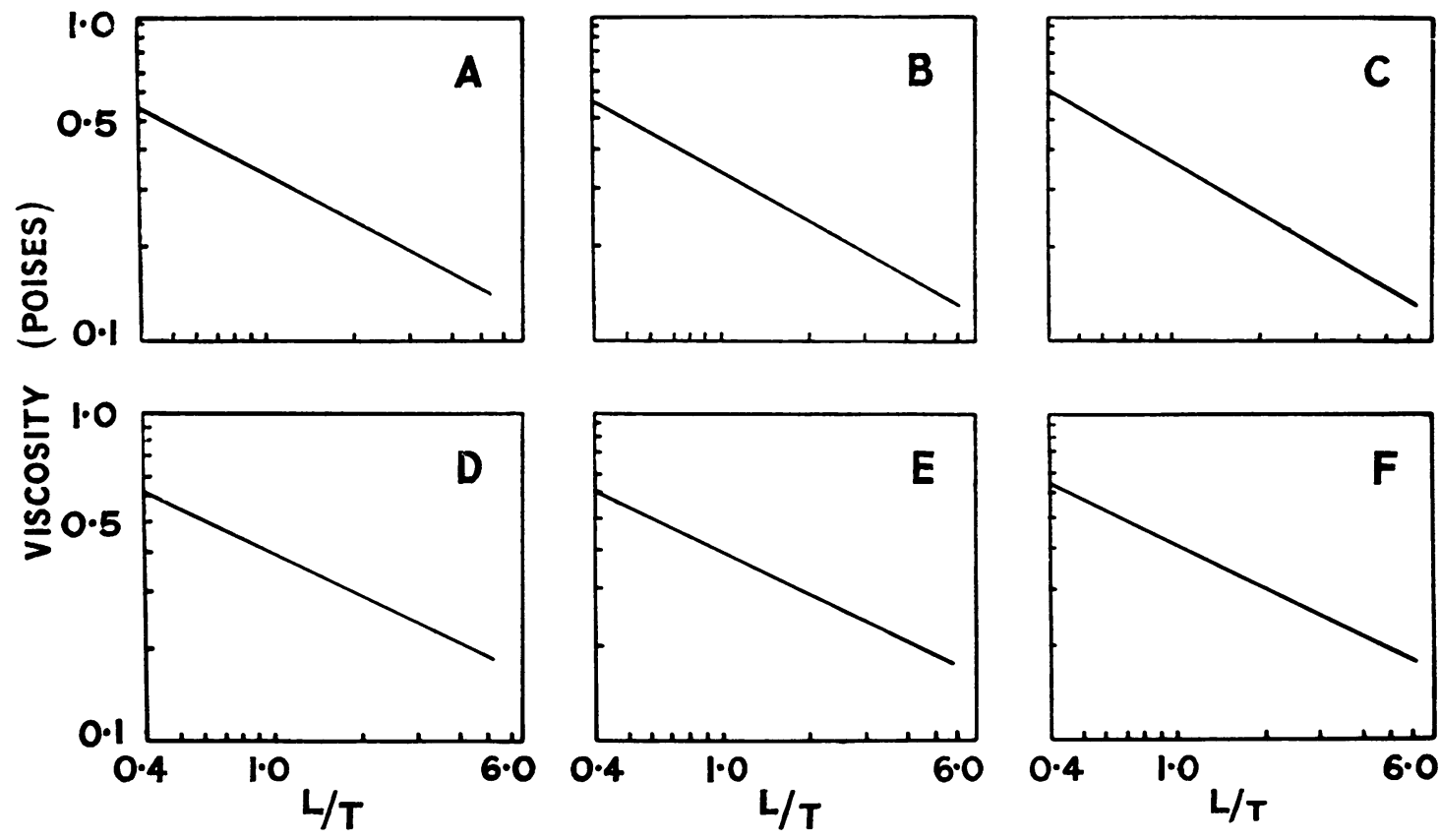

Fig. 5.-Knee fluids of patient A.J. (rheumatoid arthritis). The synovial fluid viscosity is hardly affected by either drug.

A. No treatment for 2 months.
B. One week after treatment with drug $X$.
C. One week later-very slight improvement.

(1944), based on a large number of measurements in cattle, depends to a considerable extent on the fact that the anomalous viscosity was not taken into account; few workers before Ogston and Stanier (1953) appreciated the importance of this. The remarkable discrepancies in the literature-the normal knee fluid having a viscosity of 0.1 to 0.2 poises according to Kling (1931) and of 5.0 to 15.0 poises according to Schneider (1925) - can also be explained upon this basis. The knee fluids in the present series were much more uniform.

Synovial fluid is only one of the joint tissuesthat which is most readily obtained by biopsy. An improvement in the viscous properties of fluids taken at intervals from a pathological joint does not necessarily indicate that all the tissues are recovering. Nevertheless, there is reason to believe that it reflects a lessening of inflammatory processes (Jessar, Ganzell, and Ragan, 1953). Taken in conjunction with other tests, such as those of Fletcher, Jacobs, Rose, Hess, and Markham (1954), and with the clinical picture, viscosity determinations can provide a valuable objective guide to the effect of any new drug that is being tested.

\section{Summary}

A technique is described for measuring the viscosities of normal and pathological synovial
D. After 6 weeks without treatment.
E. One week after treatment with drug Y.
F. One week later-very slight improvement.

fluids at different rates of shear. Known pressures are applied to a column of fluid within a capillarytube, and the rate of expulsion of the fluid is? measured. By recording the results graphically on double-logarithmic graph paper, samples of synovial fluid may be compared with respect to viscosity in poises and degree of polymerization of the contained hyaluronic acid molecules.

The literature is discussed with special reference to the importance of obtaining several viscosity readings at low shear rates, when the anomalous properties of synovial fluid are most marked.

I am indebted to Mr. G. Sprigg for supplying many samples of synovial fluid and to Prof. D. V. Davies for helpful advice.

\section{REFERENCES}

Barnett, C. H. (1956). J. Bone Jt Surg., 38B, 567.

(1957). Phys. in Med. Biol., 1, 380.

Bauer, W., Ropes, M. W., and Waine, H. (1940). Physiol. Rev., 20, 272 .

Blair, G. W. Scott, Williams, P. O., Fletcher, E. T. D., and Markham, R. L. (1954). Biochem. J., 56, 504.

Charnley, J. (1954). Brit. med.J., $2,1350$.

Davies, D. V. (1944). J. Anat. (Lond.), 78, 68

Davies, D. V. (1944). J. Anat. (Lond.), 78, 68. 1 . Clin. Sci., 12, 15

Dixon, A.St. John, and Bywaters, E. G. L. (1953). Clin. Sci., 12, 15. Markham, R. L. (1954). "Annual Report, Dept. of Rheumatology", Royal Free Hospital, London.

Hermans, J. J. (1953). "Flow Properties of Disperse Systems", chap. 5. North-Holland Publishing Co., Amsterdam.

Jessar, R. A., Ganzell, M. A., and Ragan, C. (1953). J. clin. Invest., 32,470 .

Jones, E.S. (1934). Lancet, 1, 1426.

Jones, E.S. (1934). Lancet, 1, 1426. 543.

MacConaill, M. A. (1932). J. Anat.(Lond.), 66, 210 

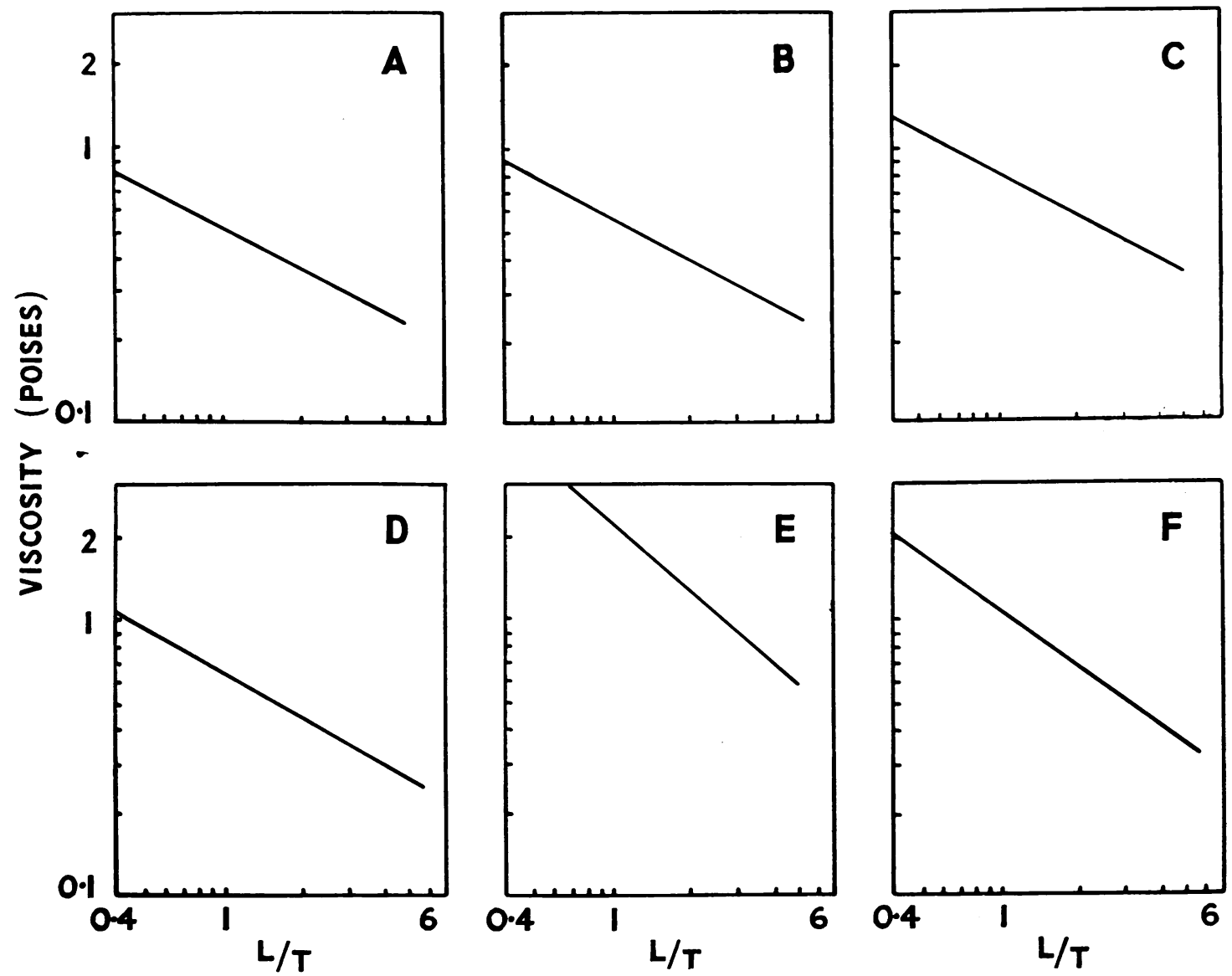

Fig. 6--Knee fluids of patient B.C. (rheumatoid arthritis). A. No treatment for 6 weeks.

B. One week after treatment with drug $\mathrm{X}$-some improvement.

C. One week later-improvement continuing.
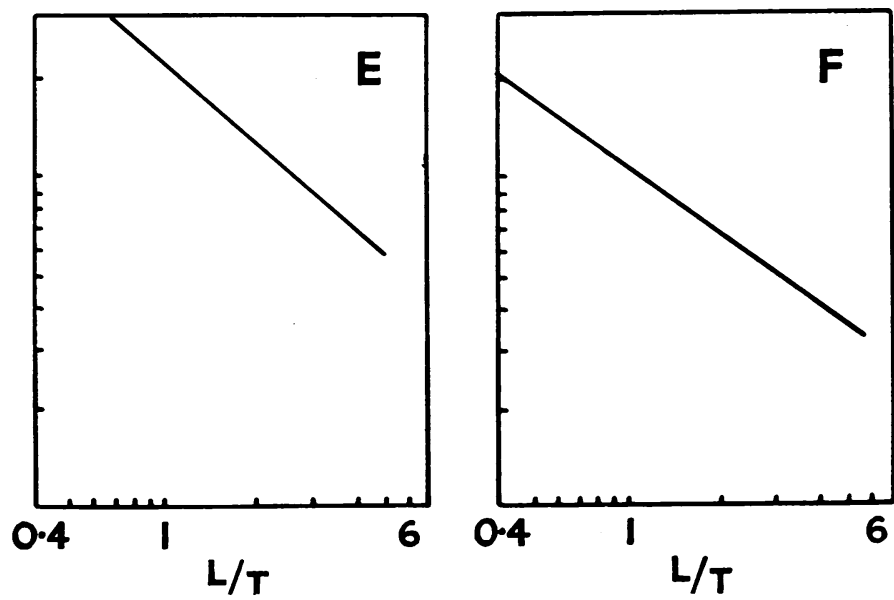

Both drugs were effective for a short period, especially $\mathbf{Y}$.

D. After 6 weeks without treatment-viscosity falling.

E. One week after treatment with drug Y-great improvement.

F. 2 weeks later-viscosity falling.

Ogston, A. G., and Stanier, J. E. (1953). J. Physiol. (Lond.), 119, 244. Ragan, C., and Meyer, K. (1949). J. clin. Invest., 28, 56.

Ropes, M. W., and Bauer, W. (1953). "Synovial Fluid Changes in Joint Disease." Harvard University Press, Cambridge, Mass. Bauer, W. (1947). Acta med. scand., 128, Suppl. 196, p. 700 . Schneider, J.'(1925). Biochem. Z., 160, 325

Sundblad, L. (1954). Scand. J. clin. Lab. Invest., 6, 288.

\section{Mesure et interprétation de la viscosité du liquide synovial}

RÉSUMÉ

On décrit un procédé pour mesurer la viscosité du liquide synovial normal et pathologique à des taux différents de cisaillement. On applique une pression connue à une colonne de liquide dans un tube capillaire et on mesure le débit d'expulsion du liquide. Après avoir enrégistré les résultat graphiquement sur un papier logarithmique double, on peut comparer les échantillons du liquide synovial en ce qui concerne sa viscosité en poises et le dégré de polymérisation des molécules d'acide hyaluronique présent.

On discute la littérature, surtout en ce qui concerne l'importance de plusieurs lectures de viscosité à des taux de cisaillement bas, quand les propriétés anormales du liquide synovial sont le plus pronocées.

\section{Medida e interpretación de la viscosidad del liquido sinovial \\ SUMARIO}

Se describe un procedimiento para medir la viscosidad del líquido sinovial normal y patológico en valores variables de la fuerza de empuje. Se aplica una persión conocida a una columna de líquido en un tubo capilar y se mide la tasa de su expulsión. Se nota el resultado gráficamente sobre papel logarítmico doble, lo que permite la comparación de los espécimenes de líquido sinovial respecto a su viscosidad en poises y el grado de polimerización de las moléculas de ácido hialurónico presente.

Se discute la literatura, particularmente respecto a la importancia de varias lecturas de viscosidad cuando la fuerza de empuje es baja y cuando las propiedades anormales del líquido sinovial son muy marcadas. 